\title{
Effects of assistance dogs on persons with mobility or hearing impairments: A pilot study
}

\author{
Diana H. Rintala, PhD; ${ }^{1-2 *}$ Rebeca Matamoros, BS; ${ }^{1-2}$ Laura L. Seitz, MA ${ }^{1,3}$ \\ ${ }^{1}$ Michael E. DeBakey Department of Veterans Affairs Medical Center, Houston, TX; Departments of ${ }^{2}$ Physical Medi- \\ cine and Rehabilitation and ${ }^{3}$ Otorhinolaryngology, Baylor College of Medicine, Houston, TX
}

\begin{abstract}
Service dogs help persons with mobility impairments by retrieving items and performing other tasks. Hearing dogs alert persons with hearing impairments to environmental sounds. We conducted a pre-post, wait list-controlled pilot study to assess the impact of the dogs on the lives of recipients. Participants were recruited through two assistance dog training organizations and completed an initial questionnaire packet. The Experimental group completed another packet 6 months after receiving a dog. The Control group completed a second packet 6 months after the initial data collection. On average, dog recipients were very satisfied with their assistance dogs. Both service and hearing dog recipients reduced their dependence on other persons. Service dog recipients reduced hours of paid assistance. No other significant change occurred in various standardized outcome measures. Assistance dogs had a major positive impact on the lives of recipients. More appropriate measurement instruments are needed to capture the impact of these dogs.
\end{abstract}

Key words: assistance, assistance dogs, deaf, disability, hearing, hearing dogs, independence, longitudinal, mobility impairment, rehabilitation, service dogs.

\section{INTRODUCTION}

Service dogs and hearing dogs are two types of assistance dogs. Service dogs help persons with mobility impairments achieve an optimal level of functional independence in activities of daily living and enhance participation in society. These dogs are trained to perform a variety of tasks, such as pulling wheelchairs, opening doors, turning on light switches, retrieving the telephone, and picking up objects such as keys. A recent study of veterans with spinal cord injuries revealed that 30 percent were interested in obtaining a service dog [1]. Hearing dogs alert persons with hearing impairments to sounds, thereby increasing these persons' safety and social interactions. The dogs are trained to alert the recipient to environmental sounds such as alarm clocks, kitchen timers, whistling teakettles, doorbells and knockers, presence of other persons, someone calling the recipient's name, smoke and fire alarms, and approaching vehicles. Only a few studies that assessed outcomes associated with obtaining an assistance dog have been published. While many studies found a positive relationship between having an assistance dog and various outcome measures, a majority of the studies were retrospective and offered limited evidence for the positive effects of assistance dogs on

\footnotetext{
Abbreviations: ANOVA $=$ analysis of variance, CHART $=$ Craig Handicap Assessment and Reporting Technique, FIM = Functional Independence Measure, M-W = Mann-Whitney, NEADS = National Education for Assistance Dog Service, SD = standard deviation, SF-12 = 12-Item Short Form Health Survey, SWLS = Satisfaction with Life Scale, THSD = Texas Hearing and Service Dogs, VHA PSAS SHCG = Veterans Health Administration Prosthetic and Sensory Aids Service Strategic Health Care Group.

*Address all correspondence to Diana $\mathbf{H}$. Rintala, PhD; 5451 Indigo Street, Houston, TX 77096; 713-664-1996.

Email: drintala@bcm.tmc.edu

DOI: 10.1682/JRRD.2007.06.0094
} 
the lives of individuals with disabilities. Furthermore, the findings of the few studies that have been completed demonstrated various inconsistencies.

\section{Social Functioning}

Early scientific studies of the effects of service dogs focused on social aspects. Both adults and children who were partnered with service dogs received more social acknowledgement from strangers than individuals who were not partnered with service dogs [2-3]. In several selfreport studies, participants with service dogs reported improvements in their social functioning [4-7]. Hearing dog users have shown similar improvements in social functioning, including increased adaptability in social situations, improved social interactions with the hearing community, and a better social life [8-11].

\section{Psychological Functioning}

Retrospective studies of individuals who had obtained a service dog also found that respondents reported positive changes in psychological functioning $[4-5,7]$. Valentine et al. found that adults with mobility impairments reported feeling more independent (90\%), having higher self-esteem (80\%), feeling more content (80\%), and being more assertive (80\%) [5]. In a pre-post study, Rintala and colleagues found that scores on a standardized self-esteem scale increased significantly from before placement to after placement of a service dog, with a notable but nonsignificant decrease in depressive symptomatology [6]. On the other hand, cross-sectional studies comparing individuals who obtained a service dog with individuals who were waiting to obtain a service dog generally found no differences in measures of self-esteem or self-concept [12-14]. In a retrospective study of 38 hearing dog owners, Hart et al. found that recipients of hearing dogs reported feeling less lonely and less stressed than before having the dog [9]. In another retrospective study of 550 hearing dog owners, Mowry et al. found that recipients reported more selfconfidence, less depression, and less loneliness than before having a hearing dog [11]. In a longitudinal prospective study, Guest et al. found significant improvements in mood, anxiety, depression, loneliness, and fearfulness [10]. On the other hand, Gilbey found no difference in reported loneliness before and after subjects received a hearing dog [15].

\section{Activities of Daily Living}

In retrospective studies of individuals partnered with service dogs, participants reported improvements in carrying out tasks of daily living. Enhanced functioning was reported in self-care, chores around the home, and mobility in the home and community $[4,6-7,12,16]$. In Roth's retrospective survey, respondents reported that their service dogs assisted them with eating (22\%), dressing (20\%), retrieving the telephone (20\%), and grooming (17\%) [16]. Fairman and Huebner's participants reported "It is easier to leave my home with my service dog" (77\%) and "It is easier to use community resources with my service dog” (73\%) [7]. In studies by Mowry et al. [11], Hart et al. [9], and Guest et al. [10], participants with hearing dogs reported that the dogs alerted them to people calling them, door knocks, alarm clocks, smoke alarms, telephones, teakettles, and burglar alarms [9-11]. Participants in Mowry et al.'s study also reported increased independence after getting the dog [11].

\section{Health, Health-Related Activities, and Safety}

In retrospective studies of service dog owners, respondents reported that their dogs assisted them with health-related behaviors and that their general health had improved since obtaining a service dog [4,7]. However, in a cross-sectional study, Marks found no differences in perceived health functioning when comparing individuals who had a service dog with individuals on the waiting list for a service dog [12]. Mowry et al. found that hearing dog recipients had improved relaxation, better physical health, and increased safety compared with life without the dogs [11]. Hart et al. reported that protection was the second most common reason (after alerting to sounds) for acquiring a hearing dog [9].

We conducted our pilot study to learn how participants who were waiting for an assistance dog currently accomplished tasks that they would expect a dog to do (i.e., with human assistance, with an assistive device, independently, with or without difficulty), as well as what tasks the dogs actually did after placement. Satisfaction and problems with the dogs were also assessed after placement. In addition, we tested the following hypothesis: persons who receive a service or hearing dog would (1) be healthier, (2) be more physically independent, (3) function better, (4) be more mobile, (5) participate more in productive activities, and (6) be more satisfied with life after receiving the dog compared with before receiving the dog and compared with a wait list control group. 


\section{METHODS}

\section{Inclusion and Exclusion Criteria}

Participants were adults (18 years or older) with a mobility or hearing impairment who had applied and been approved for a service or hearing dog from either Texas Hearing and Service Dogs (THSD) or National Education for Assistance Dog Service (NEADS) between February 2004 and April 2005. They had to meet the requirements of the provider organization to which they applied. They had to be willing to participate in interviews at two time points: initially and either 6 months after receiving an assistance dog or 6 months after the initial data collection if no dog had been placed at that time.

\section{Procedures}

When a potential candidate was accepted by the organization and placed on its waiting list, the organization told him or her about our study and asked for permission to provide the research team with his or her name and contact information. If the person gave permission, the organization contacted the research coordinator and provided the contact information. The research coordinator then contacted the potential participant by telephone, e-mail, or mail and described the study. If the person indicated interest in participating, he or she was mailed a consent form and a packet of initial questionnaires. We asked each person to read the consent form and if he or she wished to participate, sign the form in the presence of a friend or family member, who also needed to sign it, and return it in the provided prestamped and addressed envelope.

Once the coordinator received the signed consent form, she again contacted the person to complete the initial questionnaires. Persons waiting for placement of a service dog primarily completed the questionnaires by telephone. The participant could also complete the forms by e-mail or regular mail if necessary. Persons waiting for placement of a hearing dog often completed the questionnaires by e-mail or regular mail because of the difficulty of doing so by telephone.

The participants who received a service dog were contacted again an average (mean \pm standard deviation [SD]) of $7.09 \pm 0.98$ months (median $=6.93$, range $=$ 5.47-9.63) from the day they received the dog to complete the follow-up postplacement questionnaires. Those who received a hearing dog were contacted an average (mean $\pm \mathrm{SD}$ ) of $6.89 \pm 0.61$ months (median $=6.62$, range $=6.33-7.93)$ from the day they received the dog to complete the follow-up postplacement questionnaires. These participants are referred to as the Experimental groups (service and hearing, respectively).

If a participant had not received a dog by the 6-month anniversary of the completion of the initial questionnaires, he or she was asked to complete a follow-up packet of questionnaires. On average, persons still waiting for a service dog completed the follow-up questionnaires $6.87 \pm$ 0.50 months (median $=6.73$, range $=6.17-7.87$ ) after the initial interview and persons still waiting for a hearing dog completed the questionnaires $6.70 \pm 0.77$ months (median $=6.62$, range $=5.87-7.70$ ) after the initial interview. These persons are referred to as the Control groups (service and hearing, respectively). Some persons did not complete a second survey and are referred to as the Dropout groups (service and hearing, respectively). Two persons completed the 6-month follow-up because they had not yet received a service dog, later received a dog, and therefore completed a third packet of questionnaires 6 months after receiving the dog. Thus, they are represented in both the Experimental and Control groups. In effect, they served as their own controls.

\section{Measures}

A summary of the measures is provided in Table 1. Initially, we asked participants to complete a checklist of tasks that an assistance dog might do. The task lists, one for service dogs (36 items) and one for hearing dogs (17 items) were derived from longer lists developed by a work group established by the Veterans Health Administration Prosthetic and Sensory Aids Service Strategic Health Care Group (VHA PSAS SHCG). Participants could also indicate any additional tasks they would expect a service or hearing dog to do that were not on the checklists. For each task, they were asked whether they currently had difficulty performing it and whether they had help from another person or used an assistive device to accomplish it. The checklist was repeated at the second interview. However, for those who had already received dogs, the questions were asked with regard to what the dogs actually did rather than what would be expected. The participants again indicated whether they had human help or used a device to accomplish each task. Standardized scales included the 12-Item Short Form Health Survey (SF-12) [17]; the Functional Independence Measure (FIM) Motor subscale [18]; the Craig Handicap Assessment and Reporting Technique (CHART) Physical Independence, Mobility, 
JRRD, Volume 45, Number 4, 2008

Table 1.

Summary of measures used to assess effect of assistance dogs on recipients.

\begin{tabular}{llc}
\hline \multicolumn{1}{c}{ Measure } & \multicolumn{1}{c}{ Purpose } & Administration Schedule \\
\hline $\begin{array}{l}\text { Demographic and Impairment } \\
\text { Data }\end{array}$ & $\begin{array}{l}\text { Describe participants and their disability (sex, race/ } \\
\text { ethnicity, marital status, level of education, age, and time } \\
\text { since impairment onset). }\end{array}$ & Initial interview. \\
Predog Task Checklist & $\begin{array}{l}\text { Assess how assistance dog might perform tasks currently } \\
\text { accomplished by participant (with or without difficulty, }\end{array}$ & $\begin{array}{l}\text { Initial interview, 6-month } \\
\text { follow-up predog interview. }\end{array}$
\end{tabular}

Postdog Task Checklist

Other Information About Dogs' Performance

12-Item Short-Form Health Survey [1]

Functional Independence Measure: Motor Subscale [2]

Craig Handicap Assessment and Reporting Technique: Physical Independence, Mobility, and Occupation Subscales [3] Satisfaction with Life Scale [4]
Assess how tasks are currently accomplished by participant (with or without difficulty, with their assistance dog, with human help, with device).

Assess (1) tasks participants wish dogs could do but do not do, (2) how reliably dogs do tasks they have been taught, (3) whether dogs decreased participants' need for assistive technology or personal assistance, (4) how satisfied participants are with dogs, and (5) any negative aspects of having assistance dog.

Self-assessment of physical and mental health.

Assess degree of assistance needed to perform 13 tasks of daily living.

Assess (1) ability to sustain customary and effective independent existence, (2) ability to move about effectively in one's surroundings, and (3) ability to occupy time in manner customary to one's sex, age, and culture.

Assess life satisfaction.
Postdog interview.

Postdog interview.
Initial interview, 6-month follow-up predog interview, postdog interview.

Initial interview, 6-month follow-up predog interview, postdog interview.

Initial interview, 6-month follow-up predog interview, postdog interview.

Initial interview, 6-month follow-up predog interview, postdog interview.

1. Ware J Jr, Kosinski M, Keller SD. A 12-Item Short-Form Health Survey: Construction of scales and preliminary tests of reliability and validity. Med Care. 1996;34(3):220-33. [PMID: 8628042]

2. Hamilton BB, Granger CV, Sherwin FS, Zielezny M, Tashman JS. A uniform national data system for medical rehabilitation. In: Fuhrer MJ, editor. Rehabilitation outcomes: Analysis and measurement. Baltimore (MD): Paul H. Brookes Publishing; 1987. p. 137-47.

3. Whiteneck GG, Charlifue SW, Gerhart KA, Overholser JD, Richardson GN. Quantifying handicap: A new measure of long-term rehabilitation outcomes. Arch Phys Med Rehabil. 1992;73(6):519-26. [PMID: 1622299]

4. Pavot W, Diener E, Colvin CR, Sandvik E. Further validation of the Satisfaction with Life Scale: Evidence for the cross-method convergence of well-being measures. J Pers Assess. 1991;57(1):149-61. [PMID: 1920028]

and Occupation subscales [19]; and the Satisfaction with Life Scale (SWLS) [20].

\section{Data Analysis}

Results were analyzed separately for service dogs and hearing dogs because the tasks they perform and the impairments of the participants are very different. We used SPSS 15.0 (SPSS Inc; Chicago, Illinois) to obtain descriptive statistics for all quantitative data, including the mean,
$\mathrm{SD}$, and range for continuous variables, and numbers and percentages for categorical variables. Skewed continuous variables (skewness $\geq 2$ ) were identified within the group applying for a hearing dog. Total and subscale scores were calculated for standardized scales. Qualitative data were organized into various categories. Characteristics of completers (Experimental and Control groups combined) versus noncompleters (Dropout groups) and Experimental groups versus Control groups were compared with $t$-tests 
for age and time since onset of mobility or hearing impairment and with chi-square tests with exact $p$-values for categorical data. The placement patterns of the two main dog training organizations were compared with chi-square tests with exact $p$-values. For the standardized measures (i.e., SF-12, FIM, CHART, and SWLS), we compared scores of the two groups (Experimental vs Control) for the initial data and separately for the follow-up data using $t$-tests for independent samples for variables that were normally distributed (i.e., all scores for the service dog applicants and the SF-12, CHART Occupation subscale, and SWLS for the hearing dog applicants) and with nonparametric Mann-Whitney (M-W) $U$ tests for the skewed variables of FIM Motor score and the CHART Physical Independence and Mobility subscales for the applicants for a hearing dog.

Initial versus follow-up scores were also compared within each group with $t$-tests for paired samples for normally distributed variables and with Wilcoxon signed rank tests for the three skewed variables in the data from the applicants for a hearing dog. Effect sizes (Cohen $d$ ) were calculated for paired normally distributed variables within groups. Repeated-measures analyses of variance (ANOVAs) were conducted for each normally distributed outcome variable to assess main effects of time and group and their interaction. For the three skewed variables for the hearing dog applicants, we calculated change scores across time by subtracting the initial scores from the follow-up scores and compared the change scores for the two groups with M-W $U$ tests.

\section{RESULTS}

\section{Participants}

\section{Applicants for Service Dogs}

Overall, 40 persons were recruited who were waiting for a service dog, 22 referred by THSD and 18 by NEADS. The mean \pm SD age was $46.0 \pm 13.7$ years (range $=21-69$ ), and the mean \pm SD time since onset of their mobility impairment was $22.4 \pm 18.2$ years (range $=$ 1-65). Thirty-five percent were men, ninety-eight percent were non-Hispanic Caucasian, and thirty-three percent were married. The majority had at least some college education. Only a few were working for pay or were in school. Sixty-three percent had mobility impairments that affected both their upper and lower body, and thirty- seven percent had impairments that affected only their lower body.

Eighteen participants (Experimental group) eventually received a service dog and completed the follow-up postplacement questionnaires; this group included the two people who were in both the Experimental and Control groups. Fifteen participants (Control group) did not receive a dog within 6 months of entering the study and completed the 6-month follow-up questionnaires. Nine persons (Dropout group) did not complete a second set of questionnaires. Men were more likely than women to drop out ( $43 \%$ vs $\left.12 \%, \chi^{2}=5.12, p=0.044\right)$. Characteristics of the Experimental, Control, and Dropout groups are presented in Table 2. The Experimental and Control groups did not significantly differ in age, time since mobility impairment onset, sex, race/ethnicity, education, marital status, area of body affected by mobility impairment, or any occupational status (e.g., working, student, and homemaker).

Of the two main organizations, THSD referred slightly more than half the eventual participants waiting for a service dog; however, because of various factors, THSD did not place as many service dogs as NEADS during the study period. THSD placed dogs with 5 (31\%) of the 16 participants referred by them who completed the study, and NEADS placed dogs with 12 (86\%) of the 14 participants referred by them who completed the study $\left(\chi^{2}=9.02\right.$, exact $\left.p=0.004\right)$. NEADS provided applicants with dogs so quickly that the vast majority of NEADS dog recipients were in the Experimental group; thus, most of the Control group members were referred by THSD. No significant difference was found in the dropout rate between the two organizations (THSD $=24 \%$, NEADS $=22 \%, \chi^{2}=0.014$, exact $p=1.000$ ). Because of the long wait time, one person switched from THSD to another organization, Patriot Paws Service Dogs, after completing the initial questionnaires. Since the study did not focus on the individual organizations but on assistance dogs in general, receiving a dog from a third organization did not disqualify this person from continuing her participation in the study.

\section{Applicants for Hearing Dogs}

Overall, 14 persons were recruited who were waiting for a hearing dog. The mean \pm SD age was $46.7 \pm$ 15.80 years (range $=21-76$ ), and the mean \pm SD time since onset of the hearing impairment was $29.36 \pm$ 18.02 years (range $=4-56)$. Three $(21.4 \%)$ were men, 
JRRD, Volume 45, Number 4, 2008

Table 2.

Characteristics of service dog applicants. Data shown as either mean \pm SD or $n(\%)$.

\begin{tabular}{|c|c|c|c|}
\hline Variable & $\begin{array}{l}\text { Experimental Group } \\
(n=18)\end{array}$ & $\begin{array}{c}\text { Control Group } \\
(n=15)\end{array}$ & $\begin{array}{c}\text { Dropouts } \\
(n=9)\end{array}$ \\
\hline Age (yr) & $49.2 \pm 10.8$ & $45.1 \pm 14.1$ & $42.9 \pm 17.9$ \\
\hline Time Since Onset of Mobility Impairment (yr) & $23.3 \pm 19.4$ & $19.3 \pm 17.3$ & $22.4 \pm 18.5$ \\
\hline \multicolumn{4}{|l|}{ Sex } \\
\hline Men & $4(22.2)$ & $4(26.7)$ & $6(66.7)$ \\
\hline Women & $14(77.8)$ & $11(73.3)$ & $3(33.3)$ \\
\hline \multicolumn{4}{|l|}{ Race/Ethnicity } \\
\hline Caucasian (not Hispanic) & $18(100.0)$ & $14(93.3)$ & $9(100.0)$ \\
\hline Hispanic & $0(0.0)$ & $1(6.7)$ & $0(0.0)$ \\
\hline \multicolumn{4}{|l|}{ Education } \\
\hline High School, GED, or Less & $3(16.7)$ & $2(13.3)$ & $0(00.0)$ \\
\hline Some College or Associate’s Degree & $6(33.3)$ & $5(33.3)$ & $4(44.4)$ \\
\hline Bachelor's Degree & 7 (38.9) & 7 (46.7) & $3(33.3)$ \\
\hline Higher Degree & $2(11.1)$ & $1(6.7)$ & $2(22.2)$ \\
\hline \multicolumn{4}{|l|}{ Marital Status } \\
\hline Never Married & $2(11.1)$ & $5(33.3)$ & $5(55.6)$ \\
\hline Married & $8(44.4)$ & $6(40.0)$ & $1(11.1)$ \\
\hline Divorced & $8(44.4)$ & $3(20.0)$ & $2(22.2)$ \\
\hline Widowed & $0(0.0)$ & $1(6.7)$ & $1(11.1)$ \\
\hline \multicolumn{4}{|l|}{ Area of Body Affected by Mobility Impairment } \\
\hline Lower Body Only & $6(33.3)$ & $6(40.0)$ & $3(33.3)$ \\
\hline Upper and Lower Body & $12(66.7)$ & $9(60.0)$ & $6(66.7)$ \\
\hline \multicolumn{4}{|l|}{ Occupational Status (not mutually exclusive) } \\
\hline Working Full-Time & $1(5.6)$ & $3(20.0)$ & $1(11.1)$ \\
\hline Working Part-Time & $2(11.1)$ & $1(6.7)$ & $2(0.0)$ \\
\hline Student Full-Time & $1(5.6)$ & $3(20.0)$ & $3(33.3)$ \\
\hline Student Part-Time & $2(11.1)$ & $0(0.0)$ & $1(11.1)$ \\
\hline Homemaker & $6(33.3)$ & $6(40.0)$ & $2(22.2)$ \\
\hline Volunteer Part-Time & $5(27.8)$ & 4 (26.7) & $4(44.4)$ \\
\hline Retired Because of Age & $4(22.2)$ & $2(13.3)$ & $2(22.2)$ \\
\hline Retired/On Leave Because of Disability & $6(33.3)$ & $3(20.0)$ & $0(0.0)$ \\
\hline Unemployed & $1(5.6)$ & $1(6.7)$ & $1(11.1)$ \\
\hline \multicolumn{4}{|l|}{ Dog Training Organization } \\
\hline THSD & $5(27.8)$ & $13(86.7)$ & $5(55.6)$ \\
\hline NEADS & $12(66.7)$ & $2(13.3)$ & $4(44.4)$ \\
\hline Patriot Paws Service Dogs & $1(5.6)$ & $0(0.0)$ & $0(0.0)$ \\
\hline
\end{tabular}

twelve (85.7\%) were non-Hispanic Caucasian, and five (35.7\%) were married. They all had at least some college education. Twelve (85.7\%) reported having a severe hearing loss and two (14.3\%) a moderate hearing loss. Six persons (Experimental group) eventually received a hearing dog and completed the 6-month follow-up postplacement questionnaires. Four persons (Control group) did not receive a dog within 6 months of entering the study and completed the 6-month follow-up question- naires. Four persons (Dropout group) did not complete a second set of questionnaires. Characteristics of the Experimental, Control, and Dropout Groups are displayed in Table 3. Of the two organizations, THSD referred more than half those recruited; however, THSD did not place as many hearing dogs as NEADS during the study period. As with service dogs, NEADS provided applicants with hearing dogs so quickly that all the NEADS dog recipients were in the Experimental group, 
Table 3.

Characteristics of hearing dog applicants. Data shown as either mean \pm SD or $n$ (\%).

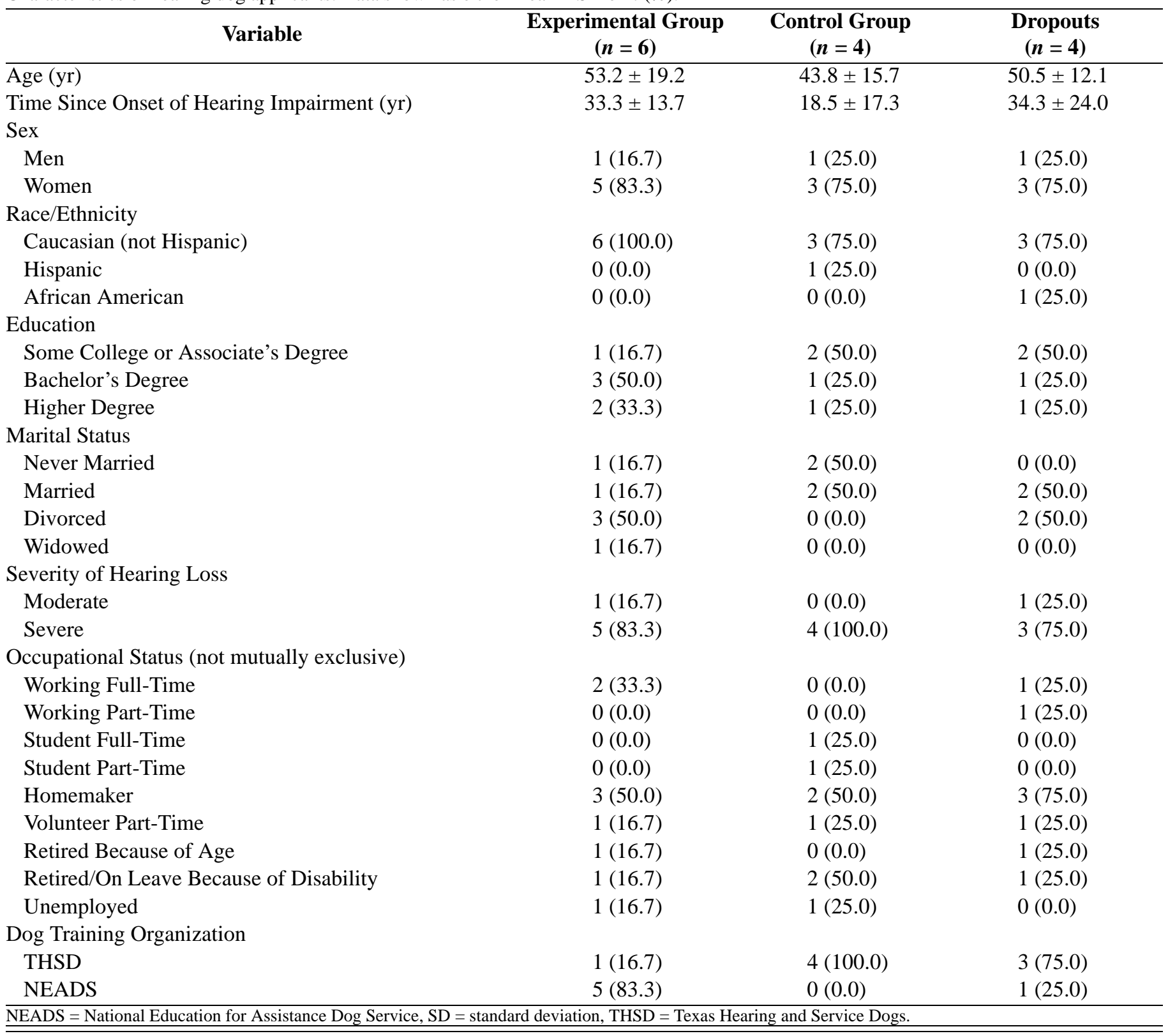

so all the Control group members were referred by THSD. The dropout rate was greater for THSD (37.5\%) than for NEADS (16.7\%).

\section{Satisfaction with Assistance Dogs}

\section{Service Dogs}

The 18 persons in the Experimental group who received a service dog indicated, on average, that they were very satisfied with the service dog; on a scale from 0 to 10 , the mean \pm SD rating was $8.94 \pm 1.35$ (median $=$ 9.00 , range $=5-10)$. All but two participants (88.9\%) rated their satisfaction with the dog as 8 or higher.

\section{Hearing Dogs}

The six persons in the Experimental group who received a hearing dog indicated, on average, that they were quite satisfied with the hearing dog; on a scale from 0 to 10 , the mean $\pm \mathrm{SD}$ rating was $7.83 \pm 1.35$ (median $=$ 
9.50, range $=1-10)$. All but one participant $(83.3 \%)$ rated their satisfaction with the dog as 7 or higher. One participant was very dissatisfied with her hearing dog because it was not adequately trained and was immature. She rated her satisfaction with the hearing dog as 1 .

\section{Perceived Positive Impact of Assistance Dogs on Participants and Others}

\section{Service Dogs}

Retrieving items was the service dog action that had the greatest positive impact on 78 percent of the participants' daily activities. Provision of emotional support and companionship by the dogs was mentioned by 44 percent of the participants as having a major impact. Other tasks mentioned as having the greatest impact included the dog helping the participant stand, walk, and balance; carrying things; turning on and off lights; opening doors; and barking to alert family members to let the participant in the house.

All but one participant with a service dog indicated that the dog made a positive difference in the lives of family members, friends, and/or attendants. In addition to having a positive emotional effect on these persons, some participants mentioned that they depended less on other persons for help. One person noted that family members felt more secure about the participant's situation because she had a dog. Another mentioned that family members preferred having the dog in their vehicles rather than a scooter or other assistive device.

\section{Hearing Dogs}

Alerting to sounds such as the telephone or alarm clock ringing was the most frequently mentioned hearing dog action that had the greatest impact on the participants' daily activities. Provision of companionship by the dog also was important to several participants. Four of the six participants with a hearing dog indicated that the dog made a positive difference in the lives of family members, friends, and/or attendants. One person noted that family members felt more secure about the participant's situation after she received her hearing dog, particularly since the participant had bipolar disease. Others noted that the dog improved the mood of family members.

\section{Perceived Negative Aspects and Costs of Having Assistance Dogs}

\section{Service Dogs}

When asked what negative aspects of having a service dog, if any, they had encountered, 11 (61\%) of the 18 participants responded. Some reported unwanted attention in public, including being challenged about bringing the dog into a restaurant. Others mentioned that the dog needed a lot of attention, woke up too early, shed fur all over, and explored the trash. The cost of caring for the dog was also mentioned. Mean \pm SD out-of-pocket costs from the time the service dog was placed with the participant to the date of the postplacement interview were $\$ 1,105 \pm \$ 1,812$ (median $=\$ 482$, range $=\$ 175$ $\$ 6,500)$. The highest cost resulted when one participant paid \$6,500 to the organization (Patriot Paws Service Dogs) that trained the dog. The second highest cost $(\$ 5,500)$ was primarily the result of a dog's unexpected surgery costs.

\section{Hearing Dogs}

When asked what negative aspects of having a hearing dog, if any, they had encountered, one participant reported no negative aspects and the other five indicated some negative aspects. Two of the five who reported some negative aspects were concerned about times they were challenged about bringing the dog into some establishment. Ensuring that all the dog's needs were taken care of, especially when the recipient was ill, was noted as a problem. The dog that was poorly trained was a hardship on the recipient. Mean \pm SD out-of-pocket costs from the time the hearing dog was placed with the participant to the date of the postplacement interview were $\$ 785 \pm \$ 606$ (median $=\$ 780$, range $=\$ 100-\$ 1,800$ ) .

\section{Tasks Carried Out by Assistance Dogs}

\section{Service Dogs}

The most frequent task routinely done by the service dogs was retrieving items (Figure 1). Nearly 90 percent of the 18 persons in the Experimental group reported retrieval as a task accomplished by the dogs. Other service dog tasks reported by at least 50 percent of the participants were carrying items by mouth, barking in an emergency, opening and/or closing external doors, carrying items in a "doggy backpack," opening and/or closing interior doors, and pushing buttons to activate automatic 
RINTALA et al. Assistance dogs

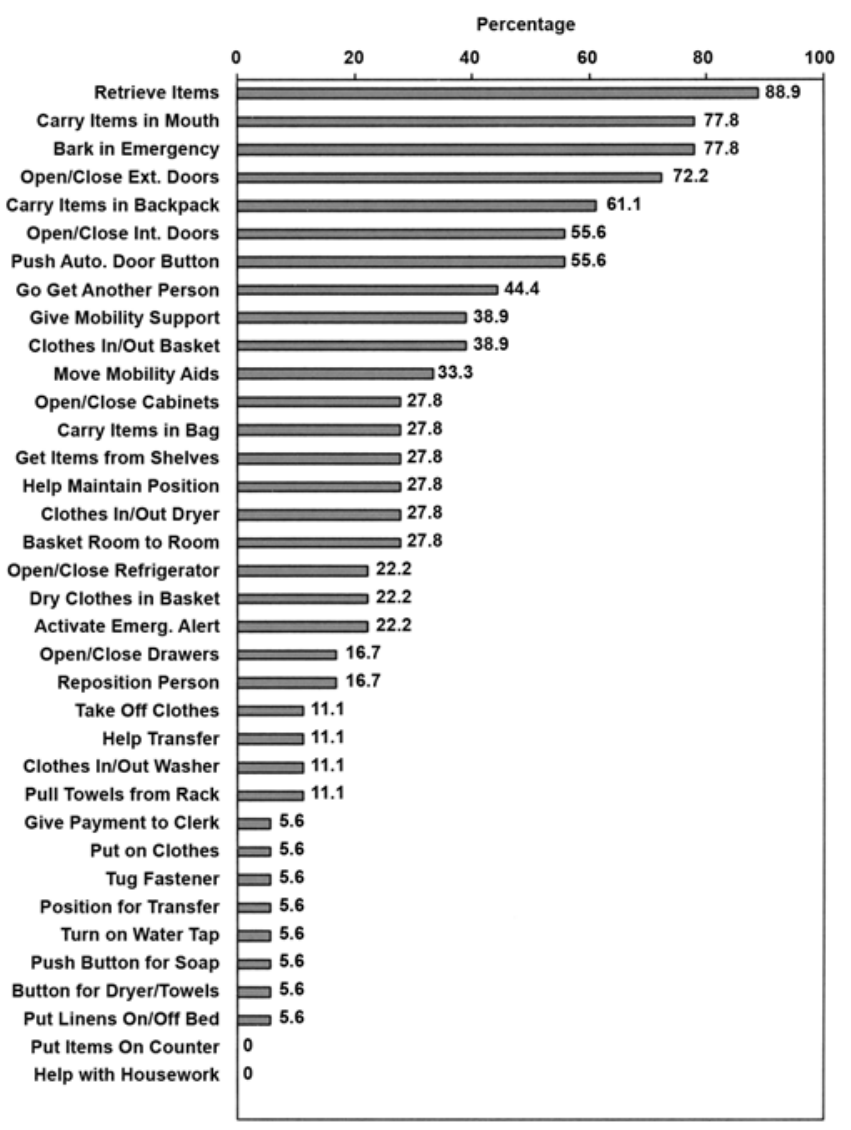

Figure 1.

Percentage of service dogs who performed each task on checklist. Auto. $=$ automatic, Emerg. = emergency, Ext. = exterior, Int. = interior.

door openers. Of the 36 tasks on the checklist, only 2 (put items on checkout counter and help with housework) were never reported as actions done by a service dog. However, 8 tasks were selected by only one person each.

\section{Hearing Dogs}

The most frequent tasks routinely done by hearing dogs were alerting to a knock on the door or the doorbell ringing, alerting to smoke or fire alarms, and barking on command (Figure 2). All six hearing dogs did all three of these tasks. At least 50 percent of the dogs performed eight other tasks.

\section{Desired Tasks Assistance Dogs Did Not Do or Did Not Do Well}

\section{Service Dogs}

Eight of the eighteen participants with service dogs indicated one or more tasks that they would like the dogs

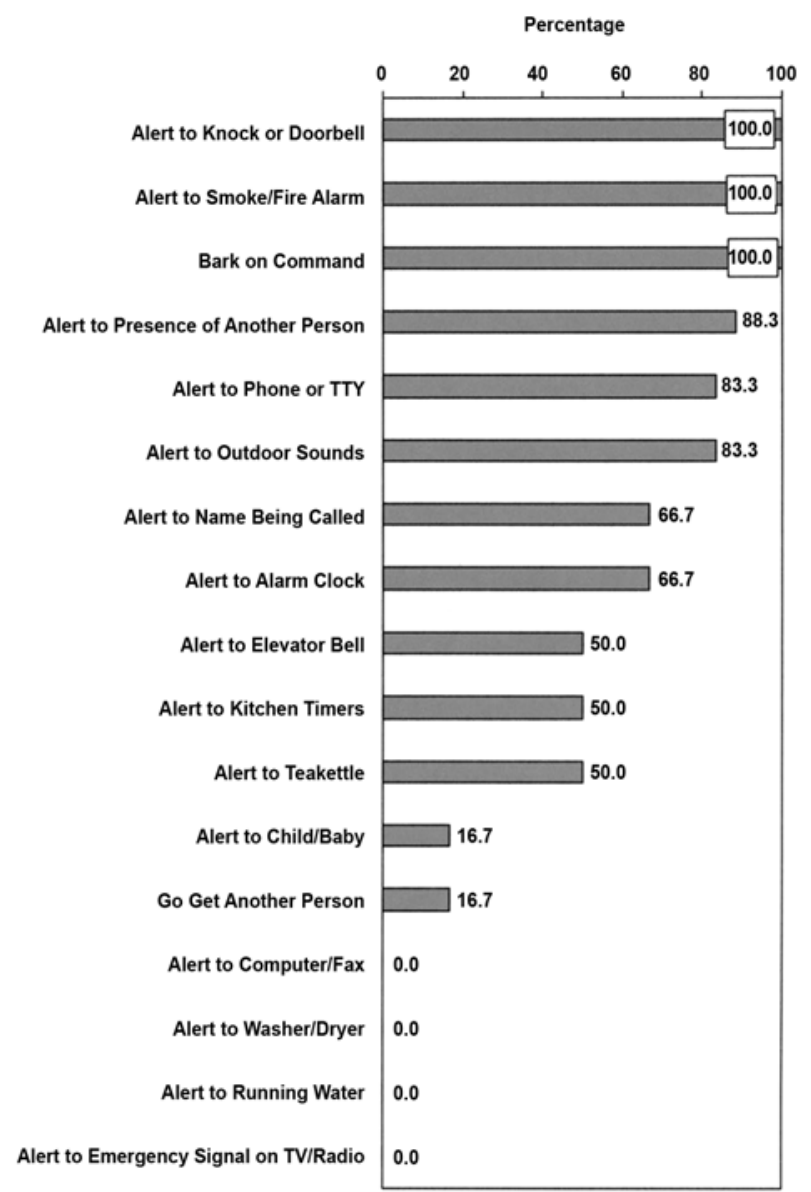

Figure 2.

Percentage of hearing dogs who performed each task on checklist. TTY = teletypewriter.

to do but for which the dogs had not been trained. Some participants mentioned that the dog was not strong or tall enough to do the desired tasks. Strength and/or size problems may have been the issue for participants who wanted the dog to pull a wheelchair, carry shopping bags, get on the bed unaided, help with laundry, and help with walking. Six persons mentioned tasks that the dogs were supposedly trained to do but which they did not do well. Several dogs had a problem with obedience, at least in certain situations, and one walked too fast for the participant.

\section{Hearing Dogs}

Only one person described tasks that she would like the hearing dog to do but for which the dog had not been trained: alerting her to running water and when she has dropped something. Two participants mentioned tasks that the hearing dogs were supposedly trained to do but 
which they did not do well: waking them up in the morning and alerting them to the ringing of a telephone.

\section{Problems with Training}

\section{Service Dogs}

When asked whether the service dog was adequately trained when it was received, 3 (16.7\%) of the 18 participants said no. One participant reported that the dog was afraid of noises, strangers, etc.; was a bundle of energy; and still seemed like a puppy. The second participant reported that the dog was not well trained in basic obedience and was not trained to do the tasks the participant needed. The third participant said the dog had to be retrained in the participant's environment because it did not generalize well. This participant wished that the inhome trainer had continued advising and providing him with backup training longer. Only one participant reported receiving inadequate training on working with the dog because the regular trainer was sick for 3 days of the 10-day training program. Another participant mentioned that the training manual needed to be updated.

\section{Hearing Dogs}

The participant who was very dissatisfied with her hearing dog reported that the dog had no experience, although it was supposed to have been fully trained. She said that fox terriers do not really mature until they are 3 years old, she could not take him anywhere, and he created an enormous hardship in her life. In terms of the training that this participant received, she said that the training organization led one to believe that it was the user's fault if problems occurred. She subsequently obtained the services of another trainer.

\section{Change in How Tasks Are Accomplished}

\section{Service Dogs}

The proportion of service dog recipients receiving help from another person decreased for 18 tasks from baseline to follow-up. These tasks included retrieving items (38.9\% to $0 \%)$, pulling towels from a rack and placing them in a hamper (38\% to $11 \%$ ), carrying a bag (27.8\% to 5.6\%), picking items off store shelves (44.4\% to $22.2 \%$ ), helping pull linens from beds and/or pull clean linens into place (61.1\% to $44.4 \%)$, and activating emergency call devices (22.2\% to $5.6 \%$ ).
This reduction in the amount of assistance from other persons with various tasks was also reflected in one item from the Independence subscale of the CHART, which measures the number of hours of paid assistance received each day. The Experimental group had a daily mean \pm SD of $4.5 \pm 6.9$ hours (median $=1.5$, range $=0-24$ ) of paid assistance at baseline and only $2.9 \pm 6.7$ hours (median $=$ 0 , range $=0-9$ ) at follow-up (Wilcoxon $Z=2.329, p=$ 0.02). The Control group did not significantly change paid assistance hours (baseline: mean \pm SD $=2.4 \pm$ 2.6 hours, median $=2.0$ vs follow-up: mean $\pm \mathrm{SD}=$ $1.67 \pm 2.6$ hours, median $=0.0$, Wilcoxon $Z=0.802, p=$ 0.42 ). Paid assistance did not significantly differ between the Experimental and Control groups at either time point. Nonparametric analyses were used because the distribution of paid hours of assistance was quite skewed.

Six (33\%) of the eighteen persons in the Experimental group indicated they no longer used at least one assistive device because of the help provided by a service dog. Five participants reported that they no longer needed to use a reacher. One participant reported that the amount of time she used her cane, scooter, wheelchair, and walker was greatly reduced after getting her service dog. Another participant stated that he used his walker less when he was out of the car as long as he did not have too far to go. Three participants mentioned devices that did a better job than the service dog. One person mentioned that the dog did not like to go under something (e.g., under a bed) to retrieve things, so the participant had to use a reacher instead. The same dog did not carry bags in her mouth, so the participant used a cargo net. The second participant mentioned that her walker did a better job of stabilizing her than the dog. The third participant mentioned that some objects were difficult for the dog to pick up, such as a piece of paper; the dog accidentally ripped it with her teeth when trying to pick it up.

How did life change from before to after dog placement? Seven participants, who initially had human help with retrieving items, had help with retrieval only from their service dogs after placement. Three participants who had used a device for retrieval only had help from their dogs after placement. Eight participants who had been independent in retrieval had help from their dogs after placement. However, all but one of those eight had indicated that retrieving items themselves was difficult. Participants also reported changes in level of concern about opening and closing external doors. Two of three participants who received human help with opening and closing 
external doors before placement had help only from their service dogs after placement. Nine participants who were able to open and close external doors independently but with difficulty and one who did not have difficulty only received help with this task from their dogs after placement. Two of three participants who had used a device for opening external doors had their dogs do it after placement.

\section{Hearing Dogs}

The proportion of hearing dog recipients receiving help from another person decreased for all 17 tasks from baseline to follow-up; however, the hearing dogs never performed 4 of these tasks. Of the other 13 tasks, the greatest reductions in human assistance were found for alerting the participant to his or her name being called (83.3\% to $16.7 \%$ ), alerting to a knock on the door or the doorbell ringing (83.3\% to $16.7 \%$ ), alerting another person in an emergency (66.7\% to $16.7 \%)$, and alerting to an elevator bell (66.7\% to $16.7 \%)$.
Two of the six persons in the Experimental group indicated they no longer used at least one assistive device because of having a hearing dog. One said she no longer needed an alarm clock with a flashing light. The other said she no longer used the flashing lights for the telephone ringing, but when the dog alerted her, she still looked to see whether the light was flashing. One person mentioned a device that did a better job than the hearing dog: a light that blinks when the telephone rings during the night.

\section{2-Item Short Form Health Survey}

Scores on the Physical and Mental components of the SF-12 can range from 0 to 100 , with higher scores indicating better health status. No significant difference existed across time within groups (pre- to post-dogplacement) or between groups at either initial or followup time points on the Physical and Mental components of the SF-12 for either service or hearing dog applicants (Table 4). For both the service and hearing dog groups,

Table 4.

Standardized outcome measures for service and hearing dog applicants assessed initially and either 6 months after receipt of dog (Experimental group [Exp]) or 6 months after initial assessment (Control group [Ctrl]).

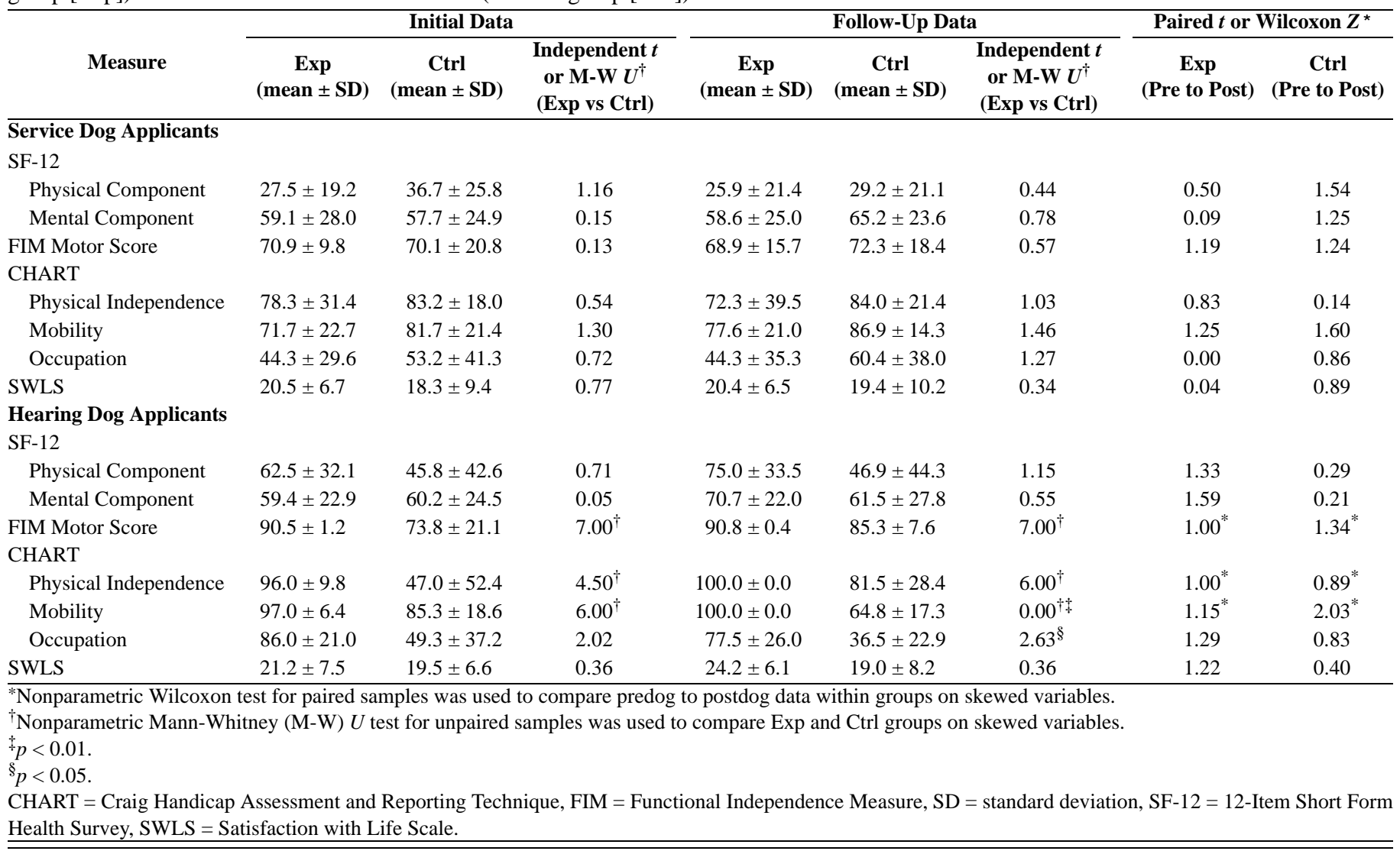


repeated-measures ANOVAs revealed no significant main effect of time or group and no interaction of the two for either the Physical or Mental component (Table 5). However, the Experimental group who received a hearing dog had medium effect sizes for both the Physical and Mental components (Cohen $d=0.54$ and 0.65, respectively), whereas the Control group for hearing dogs had very small effect sizes for the Physical and Mental components (Cohen $d=0.15$ and 0.10 , respectively).

\section{Functional Independence Measure Motor Score}

The maximum score on the FIM Motor subscale is 91, with higher scores indicating greater functional independence. For both the service and hearing dog applicants, the FIM Motor score did not significantly change from the initial to the follow-up data collection for either the Experimental or Control group and the two groups were not significantly different from each other at either time point (Table 4). FIM Motor scores were highly skewed for the hearing dog applicants. A repeatedmeasures ANOVA found no significant main effect of time or group or their interaction for service dog applicants (Table 5), and an M-W $U$ test found no significant difference between Experimental and Control groups in the amount of change in FIM Motor scores for hearing dog applicants (Table 6).

\section{Craig Handicap Assessment and Reporting Technique Physical Independence, Mobility, and Occupation Subscales}

The maximum score on each CHART subscale is 100, with higher scores indicating better functioning. Among the service dog applicants, none of the three subscales significantly differed within either group across time or between groups at either time point (Table 4). Repeatedmeasures ANOVAs revealed no significant effects of time or group or their interaction for any of the three subscales (Table 5). For hearing dog applicants, the CHART Physical Independence and Mobility subscales were highly skewed, so nonparametric statistics were used. For the Physical Independence subscale, no significant difference was found between or across groups (Table 4) and the change in score did not differ between the Experimental and Control groups (Table 6). However, for the Mobility subscale, a significant group difference was found at follow-up for the hearing dog applicants, with the Experimental group having greater mobility than the Control group (Table 4). On the other hand, the change in mobility was greater for the Control group (Table 6).

Table 5.

Repeated-measures analysis of variance of measures used to assess effect of assistance dogs on recipients.

\begin{tabular}{|c|c|c|c|c|c|c|}
\hline \multirow{2}{*}{ Measure } & \multicolumn{2}{|c|}{ Time Main Effect } & \multicolumn{2}{|c|}{ Group Main Effect } & \multicolumn{2}{|c|}{ Time $\times$ Group Interaction } \\
\hline & $F$ & $p$-Value & $F$ & $p$-Value & $F$ & $p$-Value \\
\hline \multicolumn{7}{|l|}{ Service Dog Applicants } \\
\hline SF-12 & & & & & & \\
\hline Physical Component & 2.57 & 0.119 & 0.76 & 0.390 & 1.07 & 0.309 \\
\hline Mental Component & 0.86 & 0.371 & 0.11 & 0.748 & 1.06 & 0.312 \\
\hline FIM Motor Score & 0.003 & 0.956 & 0.06 & 0.816 & 2.93 & 0.097 \\
\hline Physical Independence & 0.29 & 0.596 & 0.83 & 0.370 & 0.50 & 0.485 \\
\hline Mobility & 3.47 & 0.072 & 2.26 & 0.143 & 0.01 & 0.906 \\
\hline Occupation & 0.56 & 0.461 & 1.17 & 0.287 & 0.56 & 0.461 \\
\hline SWLS & 0.27 & 0.605 & 0.35 & 0.556 & 0.34 & 0.567 \\
\hline \multicolumn{7}{|l|}{ Hearing Dog Applicants } \\
\hline Occupation & 2.09 & 0.187 & 6.30 & 0.036 & 0.08 & 0.779 \\
\hline SWLS & 0.60 & 0.462 & 0.64 & 0.445 & 1.17 & 0.311 \\
\hline
\end{tabular}


Table 6.

Nonparametric tests of change for hearing dog applicants.

\begin{tabular}{lcc}
\hline \multicolumn{1}{c}{ Test } & Mann-Whitney $\boldsymbol{U}$ & $\boldsymbol{p}$-Value \\
\hline $\begin{array}{l}\text { Change in FIM } \\
\text { Motor Score }\end{array}$ & 7.00 & 0.352 \\
$\begin{array}{l}\text { Change in CHART } \\
\quad \text { Physical Independence }\end{array}$ & 7.00 & 0.352 \\
$\quad$ Mobility & 0.00 & 0.010 \\
\hline $\begin{array}{l}\text { CHART = Craig Handicap Assessment and Reporting Technique, FIM = Func- } \\
\text { tional Independence Measure. }\end{array}$ \\
\hline \hline
\end{tabular}

Rather than increased mobility for the Experimental group, the difference was almost wholly due to decreased mobility for the Control group, from an initial score of 85 to a follow-up score of 65. A significant difference was also found between the groups at follow-up for the Occupation subscale (Table 4), with the Experimental group having higher scores; a repeated-measures ANOVA revealed a significant main effect of group (Table 5). However, instead of higher Occupation scores in the Experimental group, both the Experimental and Control hearing dog groups had lower Occupation scores at follow-up than at baseline (Cohen $d=-0.53$ and -0.41 , respectively).

\section{Satisfaction with Life Scale}

Life satisfaction did not significantly change between the initial and follow-up contacts for either the service or hearing dog applicants. The groups did not significantly differ at either point in time for either the service or hearing dog applicants (Table 4). Repeated-measures ANOVAs found no significant main effect of time or group or their interaction for either service or hearing dog applicants. However, for the Experimental group who received hearing dogs, a medium positive effect size $(d=$ 0.50) existed, while for the Control group for hearing dogs, a small effect existed indicating that satisfaction with life had decreased a little from baseline $(d=-0.20)$.

\section{DISCUSSION}

\section{Service Dogs}

One can clearly see from the responses of the Experimental group participants that their service dogs performed many different tasks for them and, on the whole, they were quite satisfied with the dogs. The evidence indicates that those receiving a dog depended less on assistance from other persons for many of the tasks that could be performed by a service dog. Particularly heartening is the fact that hours of paid assistance decreased significantly after placement of a service dog.

On the other hand, no improvements were found in measures such as physical independence, as measured by the FIM and the CHART; mobility and productive use of time, as measured by the CHART; physical or mental health status, as measured by the SF-12; or satisfaction with life, as measured by the SWLS. One possible explanation is that the 5.5 to 9.6 months that the participants had had their service dogs at the time of the follow-up data collection were not enough to improve these major life areas. Some participants were still training the dogs at the time of the postplacement interview. Another possible explanation is that the selected outcome measures do not adequately measure the effect of the dogs. For example, the most frequently mentioned task the dogs did was retrieving items and this task is unlikely to have significantly affected whether a person secured and maintained paid employment or experienced chronic pain that interfered with activities. The positive effect on activities of daily living and mobility reported by Roth [16], Fairman and Huebner [7], and others [4,6,12] may have resulted from asking questions in a different way. Unlike Fairman and Huebner [7] and Lane et al. [4], we did not find improved health status after placement of a service dog, which is similar to Marks's findings [12]. Furthermore, our study did not measure social participation, selfesteem, depression, stress, and loneliness, because these areas had already been studied more than other areas of life also of interest; thus, the effect of the service dogs in this study on these areas cannot be measured and compared with other studies on these aspects of life.

The effect of the dogs on the participants' lives was in the realm of small but important happenings throughout the day. Imagining oneself unable to pick up items that are either out of reach or have been dropped or unable to open a door, one can appreciate the frustration resulting from having to do without an item or from waiting to go through a doorway until someone helps. To persons without disabilities, these frustrations may seem unimportant when weighed against the cost of a trained service dog. However, to the person living with the limitations imposed by a disability, having a dog perform these sorts of tasks can make a huge difference in the flow of daily life. 
As noted in the "Introduction," a large percentage of persons with severe mobility impairments are interested in obtaining service dogs [1]. If more funding were available for training assistance dogs, some of the problems caused by dogs not meeting the expectations of the recipients might be overcome. In addition, waiting times could be shortened, dogs and the needs of the recipients could be better matched, and longer follow-up training and advice could occur.

\section{Hearing Dogs}

Because the sample size for the hearing dog component was so small, making many definitive statements is unwise and statistical results must be interpreted with great caution. However, lessons regarding hearing dogs can be learned from this pilot project. One important methodological issue is the absence of appropriate measures of the effect of hearing dogs on recipients' lives. Certainly the FIM Motor score was inappropriate for this group, who, for the most part, were totally independent in activities of daily living such as those assessed with the FIM Motor score. Even the CHART and SF-12 do not appear to target the changes that occur after a person gets a hearing dog. The effect of a hearing dog was primarily one of safety (e.g., smoke and fire alarms sounding, teakettle whistling, car horn honking) and ease of going through one's day (telephone ringing, someone knocking on the door, someone calling one's name). A few of the participants indicated they no longer needed certain assistive devices, but the ones they noted were not particularly costly. However, although they may have had devices in place at home (e.g., a blinking light indicating that the telephone is ringing), these devices were not likely to be in all the places where the person might go. The dog can go almost everyplace the person goes. The major problem with one of the six hearing dogs placed during this study was insufficient training. The other five participants were very satisfied with their hearing dogs. Aside from alerting the recipients to sounds, improvement in perceived safety was another major outcome of owning a hearing dog, as was also noted by Hart et al. [9].

\section{Study Limitations}

This study has several limitations. The sample size was small, particularly for the applicants for a hearing dog. The applicants were obtained through only two assistance dog training organizations, and the distribution between the Experimental and Control groups was unequal between the two organizations, with NEADS overrepresented in the Experimental group and THSD overrepresented in the Control group. Participants were not randomly assigned to Experimental or Control groups, and the research coordinator had to be aware of which group each participant was in at the time of the follow-up data collection because the questions were slightly different for those with and without a dog (actual behavior vs expectations). Little racial/ethnic diversity existed in the sample. The selected standardized measures proved to be inadequate to assess the effect of the dogs on the lives of the recipients. The outcomes did not focus on psychosocial measures, which may have more appropriately assessed the effect of the dogs. The follow-up period of $\sim 6$ months was likely too short to fully evaluate the effect of the dogs on the selected outcomes.

\section{CONCLUSIONS}

The cost of appropriately training a service or hearing dog is very high, ranging from $\$ 5,000$ to $\$ 10,000$ or more. In addition to training costs, there are the usual costs for food and veterinary care, which can skyrocket if the dog has a serious medical problem. Some candidates hired persons to provide additional training for the dogs. It has been suggested that a dog may obviate the need for some assistive equipment, thus offsetting some of the costs of the dog. However, in this study, only relatively inexpensive equipment such as reachers and blinking lights for telephones were no longer needed because of having an assistance dog.

These facts need to be weighed against the benefits recipients reportedly obtain from their assistance dogs. The vast majority of the participants in this and earlier studies say that the assistance dogs have a major positive effect on their lives. We have not yet identified valid measures by which to assess this impact in a quantitative psychometrically sound way. The traditional measures of functioning, participation, health status, and global life satisfaction such as the FIM, CHART, SF-12, and SWLS do not adequately target areas reportedly demonstrating major positive change.

\section{ACKNOWLEDGMENTS}

We wish to thank THSD and NEADS for their input while planning this study and for their assistance in identifying potential participants. 
Rebeca Matamoros in currently affiliated with the Department of Pediatrics, Endocrinology and Metabolism section, Baylor College of Medicine, Houston, Texas.

This material was based on work supported by the VHA PSAS SHCG (project B3444F).

The authors have declared that no competing interests exist.

\section{REFERENCES}

1. Brashear TA, Rintala DH. Interest in service dogs by veterans with spinal cord injuries: A pilot study SCI Psychosoc Process [serial on the Internet. 2007 Jun [cited 2007 Jun 22];20(1):[about 22 p.]. Available from: http://www.unitedspinal.org/publications/process/2007/06/27/feature-articleinterest-in-service-dogs-by-veterans-with-spinal-cord-injuries-a-pilot-study/

2. Eddy J, Hart LA, Boltz RP. The effects of service dogs on social acknowledgments of people in wheelchairs. J Psychol. 1988;122(1):39-45. [PMID: 2967371]

3. Mader B, Hart LA, Bergin B. Social acknowledgements for children with disabilities: Effects of service dogs. Child Dev. 1989;60(6):1529-34. [PMID: 2533060]

4. Lane DR, McNicholas J, Collis GM. Dogs for the disabled: Benefits to recipients and welfare of the dog. Appl Anim Behav Sci. 1998;59(1-3):49-60.

5. Valentine DP, Kiddoo M, LaFleur B. Psychosocial implications of service dog ownership for people who have mobility or hearing impairments. Soc Work Health Care. 1993; 19(1):109-25. [PMID: 8296220]

6. Rintala DH, Sachs-Ericsson N, Hart KA. The effect of service dogs on the lives of persons with mobility impairments: A pre-post study design. SCI Psychosoc Process. 2002;15(2): 65,70-82.

7. Fairman SK, Huebner RA. Service dogs: A compensatory resource to improve function. Occup Ther Health Care. 2000; 13(2):41-52.

8. Pang PE. Hearing dogs: Enhanced human adaptability [dissertation]. Dissertation Abstracts International. 1999;60(3B):1292.

9. Hart LA, Zasloff RL, Benfatto AM. The socializing role of hearing dogs. Appl Anim Behav Sci. 1996;47(1-2):7-15.
10. Guest CM, Collis GM, McNicholas J. Hearing dogs: A longitudinal study of social and psychological effects on deaf and hard-of-hearing recipients. J Deaf Stud Deaf Educ. 2006;11(2):252-61. [PMID: 16452611]

11. Mowry R, Carnahan S, Watson D. A national study of the training, selection, and placement of hearing dogs. Fayetteville (AR): University of Arkansas, Arkansas Rehabilitation Services; 1994. Rep. No.: H133B10001.

12. Marks L. The effect of service dogs on the self-concept of the physically disabled [thesis]. Miami (FL): Florida International University; 1993.

13. Rushing C. The effect of service dogs on the self-concept of spinal injured adults [dissertation]. Dissertation Abstracts International. 1995;55(9B):4133.

14. Hackett D. Levels of self-esteem in owners of service dogs [thesis]. Long Beach (CA): California State University; 1994.

15. Gilbey AP. Testing the theory that pet ownership helps to alleviate loneliness [dissertation]. Coventry (England): University of Warwick; 2003.

16. Roth S. The effects of service dogs on the occupational performance and life satisfaction of individuals with spinal cord injuries [thesis]. Chicago (IL): Rush University, Department of Occupational Therapy; 1994.

17. Ware J Jr, Kosinski M, Keller SD. A 12-Item Short-Form Health Survey: Construction of scales and preliminary tests of reliability and validity. Med Care. 1996;34(3):220-33. [PMID: 8628042]

18. Hamilton BB, Granger CV, Sherwin FS, Zielezny M, Tashman JS. A uniform national data system for medical rehabilitation. In: Fuhrer MJ, editor. Rehabilitation outcomes: Analysis and measurement. Baltimore (MD): Paul $\mathrm{H}$. Brookes Publishing Co.; 1987. p. 137-47.

19. Whiteneck GG, Charlifue SW, Gerhart KA, Overholser JD, Richardson GN. Quantifying handicap: A new measure of long-term rehabilitation outcomes. Arch Phys Med Rehabil. 1992;73(6):519-26. [PMID: 1622299]

20. Pavot W, Diener E, Colvin CR, Sandvik E. Further validation of the Satisfaction with Life Scale: Evidence for the cross-method convergence of well-being measures. J Pers Assess. 1991;57(1):149-61. [PMID: 1920028]

Submitted for publication June 22, 2007. Accepted in revised form October 15, 2007. 